University of Windsor

Scholarship at UWindsor

2009

\title{
Shifts in Metabolic Demands in Growing Altricial Nestlings Illustrate Context-Specific Relationships between Basal Metabolic Rate and Body Composition
}

\author{
Francois Vezina \\ University of Windsor \\ Oliver P. Love \\ University of Windsor \\ Mylaine Lessard \\ University of Windsor \\ Tony D. Williams \\ University of Windsor
}

Follow this and additional works at: https://scholar.uwindsor.ca/biologypub

Part of the Biology Commons

\section{Recommended Citation}

Vezina, Francois; Love, Oliver P.; Lessard, Mylaine; and Williams, Tony D., "Shifts in Metabolic Demands in Growing Altricial Nestlings Illustrate Context-Specific Relationships between Basal Metabolic Rate and Body Composition" (2009). Physiological \& Biochemical Zoology, 82, 3, 248-257.

https://scholar.uwindsor.ca/biologypub/1126

This Article is brought to you for free and open access by the Department of Biological Sciences at Scholarship at UWindsor. It has been accepted for inclusion in Biological Sciences Publications by an authorized administrator of Scholarship at UWindsor. For more information, please contact scholarship@uwindsor.ca. 


\section{Shifts in Metabolic Demands in Growing Altricial Nestlings Illustrate Context-Specific Relationships between Basal Metabolic Rate and Body Composition}

\author{
François Vézina* \\ Oliver P. Love \\ Mylaine Lessard \\ Tony D. Williams \\ Department of Biological Sciences, Simon Fraser University, \\ 8888 University Drive, Burnaby, British Columbia V5A 1S6, \\ Canada
}

Accepted 6/19/2008; Electronically Published 4/2/2009

\begin{abstract}
Basal metabolic rate (BMR) in animals is interpreted as reflecting the size and metabolic intensity of energy-consuming tissues. However, studies investigating relationships between the mass of specific organs and interindividual variation in BMR have produced inconsistent patterns with regard to which organs have the largest impact on BMR variation. Because of the known flexibility in organ mass and metabolic intensity within individual organs, relationships between BMR and bodycomposition variables are bound to be context specific. Altricial nestlings are excellent models to illustrate this phenomenon because of the extreme variation in body composition occurring during growth. Using European starlings at three age classes, we studied changes in body composition together with its effect on variation in resting metabolic rate (RMR) in order to highlight the context-specific nature of these relationships. Our data suggest a transition in metabolic costs during growth in starling nestlings. During the linear phase of growth, energy is mainly consumed by tissue-synthesis processes, with fast-growing organs having a large influence on RMR. In the plateau phase of growth, the energy expenditure is transferred to functional costs, with high-intensity organs having a predominant effect on RMR variation. Our data illustrates the context-specific nature of organ mass-metabolic rate correlations, which complicates inter- and intraspecific comparisons of BMR. In the future, such comparisons must be done while taking the physiological state of the study animal into account.
\end{abstract}

\footnotetext{
* Corresponding author. Present address: Département de Biologie, Chimie et Géographie, Université du Québec à Rimouski, 300 allée des Ursulines, Rimouski, Québec G5L 3A1, Canada; e-mail: francois_vezina@uquar.qc.ca.

Physiological and Biochemical Zoology 82(3):248-257. 2009. (C) 2009 by The University of Chicago. All rights reserved. 1522-2152/2009/8203-8103\$15.00 DOI: $10.1086 / 597548$
}

\section{Introduction}

Basal metabolic rate (BMR) is routinely interpreted as the energy consumed by the metabolically active tissues of an organism under a defined set of experimental conditions (e.g., absence of growth, postabsorptiveness, resting state and ambient temperature within the zone of thermoneutrality; Kersten and Piersma 1987; Daan et al. 1990; Piersma et al.1996). BMR therefore reflects the metabolic intensity of these tissues and may be positively correlated to the mass of certain organs if they have high energy consumption relative to other body components (e.g., heart, kidney; Schmidt-Nielsen 1984; Daan et al. 1990). Accordingly, several studies have shown positive correlations between the mass of specific organs, the so-called metabolic machinery (Williams and Tieleman 2000), and BMR in both birds and mammals (Daan et al. 1990; Konarzewski and Diamond 1995; Weber and Piersma 1996; Meerlo et al. 1997; Burness et al. 1998; Bech and Ostnes 1999; Chappell et al. 1999; Hammon et al. 2000; Johnson et al. 2001; Selman et al. 2001). However, to date there is no clear and consistent pattern emerging with regard to which organs have the greatest impact on variation in BMR (Williams and Vézina 2001). This may partly be due to within-individual flexibility in organ mass (Piersma and Lindström 1997) as well as changes in metabolic intensity within individual organs (Selman and Evans 2005; Vézina and Williams 2005). The combination of organs affecting variation in BMR at a specific time point is therefore likely to be determined by the physiological state of the animal at the time of measurement. This idea has fundamental implications for researchers interested in variation in BMR or those using BMR as a comparative reference for the energetic costs of specific activities (e.g., Drent and Daan 1980) because it implies that the relationship between body composition and BMR will always be context specific, therefore complicating both inter- and intraspecific comparisons.

Most studies examining the relationship between metabolic rate and body composition in wild birds have focused on adult (i.e., fully grown) individuals (but see Dietz et al. 1995; Bech and Ostnes 1999; Chappell et al. 1999; Moe et al. 2004, 2005). Although high levels of flexibility have been demonstrated in several organs for specific conditions in adult birds (Piersma and Lindström 1997), postnatal growth in nestlings is associated with marked changes in the absolute and relative masses of all organs together with changes in metabolic rate (Ricklef 1979; 
Dunn and Brisbin 1980; Lilja 1983, 1997; Klaassen and Drent 1991; Weathers and Siegel 1995). In the contexts of phenotypic plasticity (i.e., irreversible growth trajectory in a specific trait; Piersma and Drent 2003) and flexibility (i.e., reversible individual trait change; Piersma and Drent 2003), growing nestlings are therefore an excellent model to examine context-specific relationships between body composition and metabolic rate.

Altricial nestlings are characterized by rapid growth (Ricklefs 1973, 1979; Lilja 1983). They are generally born with disproportionately large stomachs (O'Connor 1977; Ricklefs 1979; but see Ricklefs et al. 1998) and show a high organ growth rate early after hatch (Ricklefs 1979; Lilja 1982, 1983), especially for the digestive organs and liver (Ricklefs 1967; O'Connor 1977; Lilja 1982, 1983). Organ growth rate typically slows toward the end of the nestling period until the nestling reaches adult body composition (Ricklefs 1979; Lilja 1982, 1983). Therefore, one would predict that during early postnatal development, BMR of altricial species would reflect energy investment in fastgrowing and digestive organs (e.g., Lilja 1997), while in fledglings, BMR would be affected more evenly by the ensemble of body constituents or a combination of organs similar to that found in adult individuals (see Table 1 in Piersma 2002).

In this study, we compared interindividual variation in resting metabolic rate (RMR) with variation in body composition in altricial European starling (Sturnus vulgaris Linnaeus) nestlings at three ages: (a) $5 \mathrm{~d}$ old, the period of most rapid linear growth; (b) $11 \mathrm{~d}$ old, when nestlings enter the plateau phase of the growth curve; and (c) $20 \mathrm{~d}$ old, about 2-4 d before fledging (Fig. 1). Although our measurement conditions are close to those defining BMR for adult animals (see "Material and Methods"), we worked with immature birds actively synthesizing new tissues, and our measurements were carried out during the day. We therefore consider the term RMR more appropriate for this study. Our specific objectives were to quantify the patterns of growth of the various body components and to determine how this relates to variability in RMR. More specifically, we investigated which organs were correlated with RMR at specific age stages and asked whether this changed depending on context, that is, the different stages of growth.

\section{Material and Methods}

The study was carried out at the Pacific Agri-Food Research Center in Agassiz, British Columbia, Canada $\left(49^{\circ} 14^{\prime} \mathrm{N}\right.$, $121^{\circ} 46^{\prime} \mathrm{W}$ ) during May 2001 under a Simon Fraser University animal care permit (657B-96) and following the guidelines of the Canadian Committee on Animal Care. About 175 nest boxes installed on telephone poles and farm buildings at this site were monitored daily during laying, incubation, and nestling provisioning to record clutch initiation, clutch size, and clutch mass and to mark and measure the nestlings. The nestlings collected for this study came from nests where adult females were killed for body composition as part of another experiment (Vézina and Williams 2003). Taking only one nestling per brood, a total of 53 nestlings were collected for this experiment (5 d old, $n=17 ; 11 \mathrm{~d}$ old, $n=16 ; 20 \mathrm{~d}$ old,

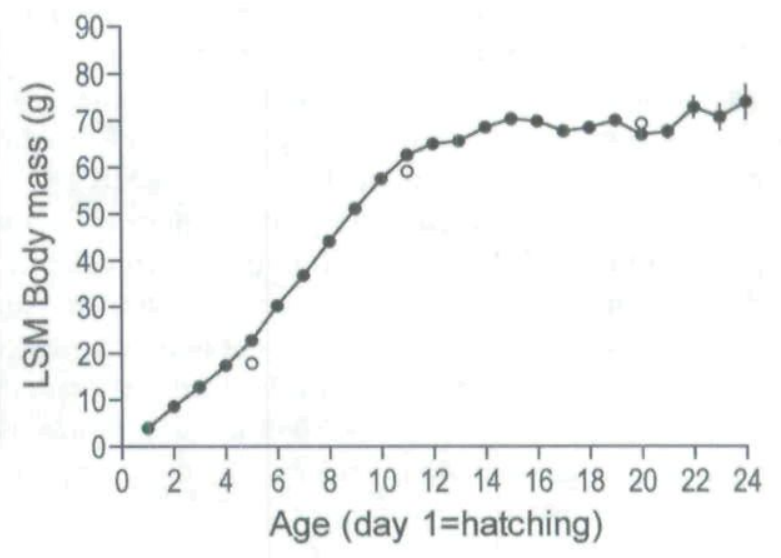

Figure 1. Body mass in relation to age in days from hatching to fledging in European starlings in 1999. Open circles represent body mass of nestlings used for resting metabolic rate and body-composition analysis in 2001. Values are least square means (LSMs) and control for brood composition (see text for details). Error bars are standard errors and are smaller than the symbols in most cases.

$n=20$ ). Daily weighing data used to generate the nestling growth curve (Fig. 1) for this population were obtained in 1999.

\section{Measurement of Resting Metabolic Rate}

Nestlings were removed from their nest boxes at night (2100 hours $\pm 1 \mathrm{~h}$ ) and kept overnight (9-11 h, depending on capture time $)$ at $30^{\circ} \mathrm{C}\left(40^{\circ} \mathrm{C}\right.$ for 5 -d-olds; see below $)$ in a temperature-controlled cabinet (PTC-1-30, Sable Systems, Las Vegas, NV) inside a cardboard box filled with facial tissues. RMR measurement started at 0700 hours the following morning, at which time all the nestlings were awake and exhibited no signs of discomfort. Each bird was placed in a separate stainless (1.40 L, 5 and $11 \mathrm{~d}$ old) or Plexiglas (3.5 L, $20 \mathrm{~d}$ old) metabolic chamber that received dry $\mathrm{CO}_{2}$-free air (scrubbed by passing the air through a Drierite and Ascarite column) at a flow rate of $550-570 \mathrm{~mL} / \mathrm{min}$ STP (measured by a mass flowmeter; model $810 \mathrm{C}$, Sierra Instruments, Monterey, CA). European starlings are not fully homeothermic and endothermic before 11-12 d of age (Clark 1982; Ricklefs and Webb 1985). We therefore maintained the ambient temperature in the cabinet at $40^{\circ} \mathrm{C}$ (i.e., normal adult body temperature; Prinzinger et al. 1991) when measuring 5-d-old individuals and at $30^{\circ} \mathrm{C}$ when measuring 11- and 20-d-old nestlings. This latter temperature is within the thermoneutral zone for adult starlings (Biebach 1979, 1984).

Oxygen content was measured in the outflow air (FC-1 analyzer, Sable Systems) by subsampling the line (air dried and scrubbed of its $\mathrm{CO}_{2}$ before $\mathrm{O}_{2}$ analysis), and the air analyzed was coming from one chamber at a time (selected with a valve multiplexer; model TR-RM4, Sable Systems). Ten minutes before and after each measurement, this air was compared with a reference air sample (also scrubbed of its water and $\mathrm{CO}_{2}$ content). For each measurement session, the birds were left in their metabolic chambers to habituate for $1 \mathrm{~h}$ before starting 
the measurements. Each chamber was sampled in a sequence for $1 \mathrm{~h}$, and $\dot{\mathrm{V}}_{2}$ was calculated using the Datacan software package (Sable Systems). RMR was designated as the lowest $\dot{\mathrm{V}}_{2}$ for 10 consecutive minutes during the hour of measurements. Measurement sequence did not affect RMR $\left(F_{3,53}=\right.$ $0.6, P=0.6)$. We do not have respiratory quotients, so we calculated a range of RMR values in $\mathrm{kJ} / \mathrm{d}$ for each age group. To do so, we used the lowest and highest possible energy conversions: $18.4 \mathrm{~kJ} / \mathrm{L} \mathrm{O}_{2}$ if the animal was consuming protein as fuel and $20.9 \mathrm{~kJ} / \mathrm{L} \mathrm{O}_{2}$ if the animal consumed carbohydrates (Schmidt-Nielsen 1990). Body mass ( $0.00 \mathrm{~g})$ was measured before and after metabolism measurements, and the average mass was used in the analysis.

\section{Body-Composition Analysis}

Following RMR measurements, each bird was killed by exsanguination under anesthesia (mixture of ketamine and xylasine $50: 50)$ and dissected for body composition. The organs collected were liver, heart (only the ventricle, because earlier tests showed better constancy in the dissection technique), kidney, gizzard, pancreas, small intestine (hereafter called "intestine," connective tissues and fat manually removed and emptied of its contents by pressing along its length with a probe), pectoral muscles (left side only; data multiplied by 2 ), and the complete left leg (thigh and calf). Leg bones in 5-d-old nestlings were soft and proved very difficult to extract from muscle tissues in a consistent manner, so for comparability, we kept the bones in with the leg muscles at all age stages. In the early stages of growth, leg bones were growing together with total leg mass as indicated by positive relationships between tarsus length (an indicator of leg bone length) and leg mass (5 d old: $r^{2}=$ $0.60, n=17, P<0.0005 ; 11 \mathrm{~d}$ old: $r^{2}=0.57, n=16, P<$ $0.001)$. By $12 \mathrm{~d}$ of age, the structural growth of the leg was nearly completed (less than $2 \%$ increase in tarsus length per day; data not shown), and thus most of the mass gain between 11 and $20 \mathrm{~d}$ of age was due to muscle tissues (no significant relationship between tarsus length and leg mass at $20 \mathrm{~d}$ of age; $P=0.4)$. Therefore, given that most of the leg muscle growth appeared late in development (between 11 and $20 \mathrm{~d}$ of age; see "Results"), we consider leg mass as a good indicator of leg muscle growth. Feathers were plucked from 11- and 20-d-old nestlings. All organs, feathers, and the remaining carcass were then frozen $\left(-20^{\circ} \mathrm{C}\right)$ for subsequent analysis. Organs were later freeze-dried (model 8ES, Virtis, New York, NY) to constant mass and fat extracted in petroleum ether using a Soxhlet apparatus. The carcasses were ground to form a homogenous powder before fat extraction. Dry body mass was calculated as dry carcass mass plus dry organ mass. Lean dry body mass was calculated as lean dry carcass mass plus the mass of the lean dry organs. Water mass was calculated as fresh body mass minus dry body mass for the 5-d-old group and fresh body mass minus dry body mass plus dry feather mass for the 11- and 20-d-old birds. Although water and fat (Scott and Evans 1992) - and, in the case of 5-d-old nestlings, yolk (Steen and Gabrielsen 1986) - have no or very low levels of energy consumption, they may nevertheless introduce a "dilution effect" in the analysis with regard to metabolic rate. We therefore analyzed lean dry body and lean dry organ mass data unless otherwise stated.

\section{Energy Investment in Tissue Accretion}

Body-composition data allowed us to calculate gross energy investment in tissue accretion during the periods of linear and plateau phases of growth. We used the measured changes in lean body mass and fat content between 5 and $11 \mathrm{~d}$ and between 11 and $20 \mathrm{~d}$ of age for these estimates. We calculated the approximate total amount of energy spent on protein and fat deposition using the costs measured by Pullar and Webster (1977). That is $1.36 \mathrm{~kJ} / \mathrm{kJ}$ for fat and $2.25 \mathrm{~kJ} / \mathrm{kJ}$ for proteins. These values include both the energy deposited in the tissue and the energy spent in the physiological processes of tissue accretion. One gram of fat and protein containing 39.36 and $17.79 \mathrm{~kJ}$, respectively (Schmidt-Nielsen 1990)—the actual energy spent in tissue accretion independent of tissue energy content-is $14.17 \mathrm{~kJ} / \mathrm{g}([39.36 \times 1.36]-39.36)$ for fat and 22.24 $\mathrm{kJ} / \mathrm{g}([17.79 \times 2.25]-17.79)$ for proteins.

\section{Statistical Analysis}

We constructed the body-mass growth curve presented in Figure 1 from 1,187 daily body-mass measurements collected on all nestlings from 29 broods. To illustrate the individual and brood-independent pattern of growth for this locality, the growth curve was generated through a repeated measure analysis (mixed general linear model) testing for age (d) while controlling for individual (nested in brood) and brood. To represent the contribution of specific organs to nestling body mass, we used the ratio of organ mass to body mass. To represent nestling organ mass as a proportion of final adult target mass, we calculated a ratio of nestling to adult organ mass using data collected on adult starlings from 1999 to 2001 (Vézina and Williams 2003). We are aware of the statistical pitfalls that may be associated with the use of ratios to normalize the effects of body mass (Blem 1984; Packard and Boardman 1988, 1999). However, in our analyses involving ratios, we do not intend to remove body-mass effects per se, but instead we wish to illustrate the relative contribution of each organ to total body mass at specific age stages. Therefore, we applied the arcsine-square root transformation to all ratio data before their analysis as advised by Zar (1996), and we tested normality of the residuals using a Shapiro-Wilk test. No deviance from normality was observed in residual data. We thus consider that the use of ratios here is not creating a systematic bias in our interpretation of growth differences between specific organs. Adult data came from nonbreeding and nestling provisioning females (we do not have body-composition data for males). Because adult body composition and body mass also vary between reproductive stages (see Vézina and Williams 2003), the target organ mass is not an absolute value, and we realize that final target mass is therefore only an approximation. Comparing differences between age classes was carried out using one- 
Table 1: Body composition, metabolic rate, and water index in nestlings collected at 5, 11, and $20 \mathrm{~d}$

\begin{tabular}{|c|c|c|c|c|c|}
\hline \multirow[b]{2}{*}{ Variable } & \multicolumn{3}{|l|}{ Age (d) } & \multirow[b]{2}{*}{$F(\mathrm{df})$} & \multirow[b]{2}{*}{$P$} \\
\hline & 5 & 11 & 20 & & \\
\hline Fresh body (g) & $17.81 \pm 3.72^{\mathrm{A}}$ & $59.13 \pm 4.52^{\mathrm{B}}$ & $69.25 \pm 4.88^{C}$ & $677.9(2,53)$ & $<.0001$ \\
\hline Fat $(\mathrm{g})$ & $.20 \pm .08^{\mathrm{A}}$ & $.99 \pm .34^{\mathrm{B}}$ & $1.38 \pm .54^{\mathrm{C}}$ & $44.0(2,51)$ & $<.0001$ \\
\hline Water (g) & $15.63 \pm 3.20^{A}$ & $46.41 \pm 3.45^{\mathrm{B}}$ & $49.95 \pm 3.97^{c}$ & $482.8(2,51)$ & $<.0001$ \\
\hline Carcass $(\mathrm{g})$ & $1.40 \pm .33^{\mathrm{A}}$ & $6.34 \pm .59^{\mathrm{B}}$ & $9.77 \pm .75^{\mathrm{C}}$ & $915.6(2,52)$ & $<.0001$ \\
\hline LD body $(\mathrm{g})$ & $2.19 \pm .51^{\wedge}$ & $9.30 \pm .80^{\mathrm{B}}$ & $13.86 \pm 1.09^{C}$ & $863.7(2,51)$ & $<.0001$ \\
\hline Feather (g) & $\ldots$ & $.93 \pm .27^{\mathrm{A}}$ & $3.42 \pm .22^{\mathrm{B}}$ & $918.1(1,35)$ & $<.0001$ \\
\hline LD liver $(\mathrm{g})$ & $.17 \pm .05^{\mathrm{A}}$ & $.72 \pm .06^{\mathrm{B}}$ & $.68 \pm .08^{\mathrm{B}}$ & $355.2(2,52)$ & $<.0001$ \\
\hline LD heart $(g)$ & $.03 \pm .01^{\mathrm{A}}$ & $.09 \pm .01^{\mathrm{B}}$ & $.13 \pm .01^{\mathrm{C}}$ & $603.0(2,52)$ & $<.0001$ \\
\hline LD kidney (g) & $.06 \pm .01^{\wedge}$ & $.21 \pm .02^{\mathrm{B}}$ & $.20 \pm .01^{\mathrm{B}}$ & $547.0(2,52)$ & $<.0001$ \\
\hline LD gizzard $(\mathrm{g})$ & $.28 \pm .06^{\wedge}$ & $.68 \pm .07^{\mathrm{B}}$ & $.66 \pm .07^{\mathrm{B}}$ & $191.0(2,52)$ & $<.0001$ \\
\hline LD pancreas $(\mathrm{g})$ & $.04 \pm .01^{\mathrm{A}}$ & $.13 \pm .02^{\mathrm{B}}$ & $.12 \pm .02^{\mathrm{C}}$ & $141.0(2,52)$ & $<.0001$ \\
\hline LD pectoral muscle $(\mathrm{g})^{\mathrm{a}}$ & $.04 \pm .01^{\mathrm{A}}$ & $.46 \pm .09^{\mathrm{B}}$ & $2.22 \pm .38^{\mathrm{C}}$ & $436.0(2,52)$ & $<.0001$ \\
\hline LD leg $(g)$ & $.11 \pm .03^{\wedge}$ & $.54 \pm .06^{\mathrm{B}}$ & $.80 \pm .05^{\mathrm{C}}$ & $860.5(2,52)$ & $<.0001$ \\
\hline LD intestine (g) & $.08 \pm .02^{\mathrm{A}}$ & $.34 \pm .05^{\mathrm{B}}$ & $.39 \pm .06^{\mathrm{C}}$ & $221.5(2,52)$ & $<.0001$ \\
\hline $\mathrm{RMR}(\mathrm{mL} \mathrm{O} / \mathrm{h})$ & $42.7 \pm 12.0^{A}$ & $155.6 \pm 27.3^{B}$ & $231.7 \pm 26.9^{C}$ & $308.8(2,52)$ & $<.0001$ \\
\hline $\operatorname{RMR}(\mathrm{kJ} / \mathrm{d})^{\mathrm{b}}$ & $19-21$ & 69-78 & $102-116$ & $\ldots$ & $\ldots$ \\
\hline Water index (g water/g LD body) & $7.2 \pm .3^{\mathrm{A}}$ & $5.0 \pm .2^{\mathrm{B}}$ & $3.6 \pm .2^{\mathrm{C}}$ & $1,078.6(2,51)$ & $<.0001$ \\
\hline
\end{tabular}

Note. Different superscript letters indicate significant difference between age classes (see text for details). Values are mean $\pm S D$. LD $=$ lean dry. $\mathrm{RMR}=$ resting metabolic rate.

" Only the left pectoral muscle was dissected; all values are multiplied by 2

${ }^{b} \mathrm{RMR}$ in $\mathrm{kJ} / \mathrm{d}$ calculated from the average value in $\mathrm{mL} \mathrm{O}_{2} / \mathrm{h}$ and based on a range of fuel from proteins to carbohydrates (see text for details).

way ANOVAs and post hoc Tukey tests on actual body composition and transformed ratio data. Relationships between continuous variables were investigated using Pearson's correlations.

There was a high level of collinearity in organ masses at all age classes, which prevented us from using a standard multiple regression approach to test for body-composition effects on RMR. To remedy this problem, we used the approach adopted by Speakman and McQueenie (1996) and Johnson et al. (2001) using principal component (PC) analyses on the correlation matrix generated from the dissection data within age classes (Jolliffe 2002). This allowed us to generate new, statistically independent, virtual variables (PC1-PC9) capturing $100 \%$ of the variation in the original data set (with $90 \%$ of the variation typically captured in the first five PCs). Each of these PCs are under the influence of specific organs or clusters of organs, which is determined by reading eigenvectors representing correlations between all nine original organ variables and each PC variable. $\mathrm{PC}$ variables are therefore interpreted as reflecting the influence of the organs with the highest eigenvectors. We then ran a stepwise multiple regression to determine which of the PC variables better described the variation in RMR for each age class. It is important to realize here that some organs may have very little impact on the variation in total body composition (e.g., high eigenvectors in PC variables explaining a fraction of the variance), but yet they may be key in explaining variation in metabolic rate. For example, some high-metabolicintensity organs known for their effects on BMR have very small relative sizes (e.g., 1\%; Daan et al. 1990). We therefore included all PC variables in the multiple regression analysis.
Results are presented as mean \pm SE unless otherwise stated, and ratio data is presented untransformed.

\section{Results}

\section{Changes in Body Composition}

As the nestlings grew, overall body mass increased significantly (Table 1). Fresh and lean dry body mass increased three- and fourfold, respectively, between 5 and $11 \mathrm{~d}$ of age (Fig. 1; Table 1). Five-day-old nestlings were on the linear part of the growth curve for this population (i.e., most rapid growth), whereas 11-d-old nestlings were entering the plateau phase of growth (Fig. 1). Between the ages of 11 and $20 \mathrm{~d}$, fresh body mass increased by $17.3 \%$, while lean dry body mass increased by $49.5 \%$ (Table 1). As the nestlings grew, the amount of body water per unit lean dry body mass, a tissue-maturation index (Ricklefs 1967, 1979; Ricklefs and Webb 1985; Starck and Ricklefs 1998), decreased. That is, older nestlings had a larger proportion of their body made up of functionally mature tissues. At $20 \mathrm{~d}$ of age, the fresh body mass of nestlings was $90 \%$ of the body mass of adults measured at the same time (nestlings $69.3 \pm 4.9 \mathrm{~g}$, adults $\left.76.9 \pm 3.7 \mathrm{~g}, F_{1,130}=67.7, P<0.0001\right)$.

Relative body composition changed markedly among the three nestling age classes (Fig. $2 A ; P<0.0001$ in all cases; see Table 1 for age effect on absolute lean dry organ mass). In 5 d-old nestlings, the largest organs in the body were the gizzard (12.8\% of lean dry body mass), liver $(7.8 \%)$, leg $(5.1 \%)$, and intestines $(3.7 \%)$, and at this age, gizzard mass was already $42.2 \%$ of its target adult mass (Fig. $2 B$ ). When entering the plateau phase of growth, at $11 \mathrm{~d}$, gizzard and liver were still 


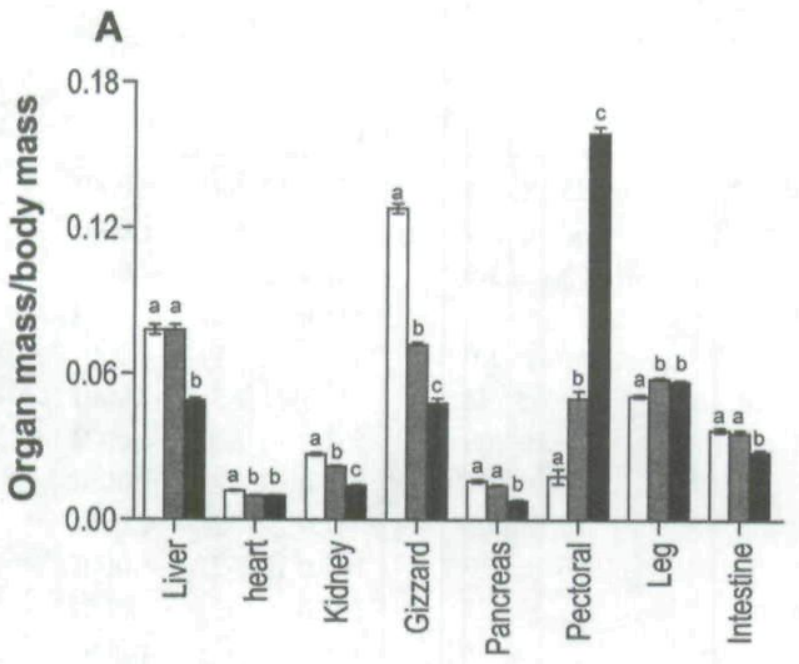

B

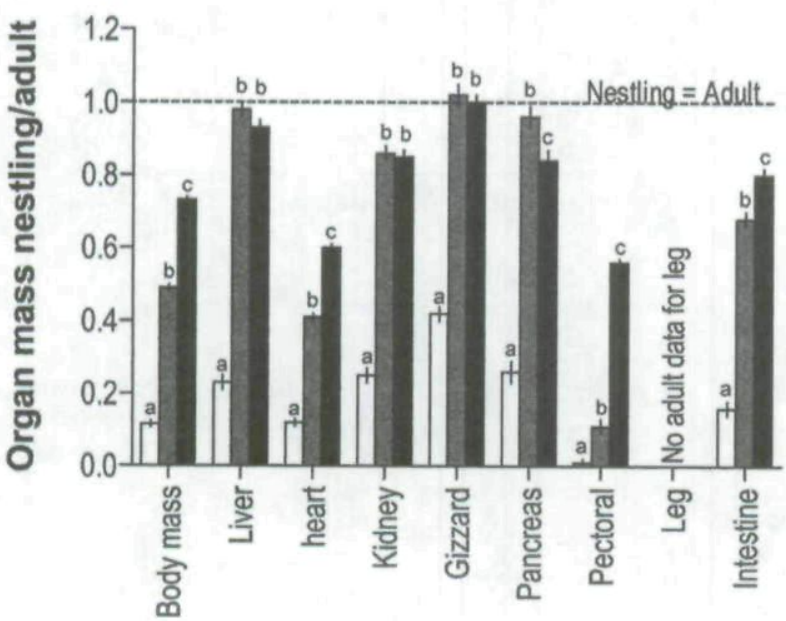

Figure 2. A, Proportion of nestling lean dry body mass occupied by the lean dry mass of specific organs within each age class. $B$, Nestling's lean dry organ mass relative to approximated adult target lean dry organ mass within age class. The dotted line represents equality between nestling and adult organ lean dry mass. Significant differences between ages within organs are represented by different letters. Statistical analyses were preformed on arcsine-square root transformed data, but the figures show untransformed values (see text for details). $\mathrm{LD}=$ lean dry. White bars $=5 \mathrm{~d}$ old, gray bars $=11 \mathrm{~d}$ old, black bars $=20 \mathrm{~d}$ old.

the largest organs in the body, but the relative contribution of the gizzard to total body mass had decreased such that both organs occupied the same proportion of total mass (gizzard $7.2 \%$ and liver $7.8 \%$, of lean dry body mass; Fig. $2 A$ ). Most of the organ growth appeared during the linear phase of growth. Indeed, at $11 \mathrm{~d}$ of age, even though lean dry body mass was only $48.9 \%$ of adult target mass, the livers, kidneys, gizzards, pancreas, and intestine of nestlings had grown to $97.7 \%, 85.9 \%$, $102.4 \%, 96.1 \%$, and $68.4 \%$ of their final adult mass, respectively (Fig. 2B)

All organs were not growing at the same speed. Indeed, absolute growth (g lean dry mass/d) between 5 and $11 \mathrm{~d}$ of age was roughly three times faster in the liver, leg, and gizzard
$(0.07-0.09 \mathrm{~g} / \mathrm{d})$ and about two times faster in the intestine $(0.04$ $\mathrm{g} / \mathrm{d})$ compared with the kidney and pancreas $(0.02-0.03 \mathrm{~g} / \mathrm{d})$. During the plateau phase of growth, most internal organs were already well developed, and much of the total lean dry mass gain was made up of growing muscles (Fig. 2A). Indeed, pectoral muscles showed the highest absolute growth rate during that period $(0.10 \mathrm{~g} / \mathrm{d})$. Even though lean dry pectoral muscle mass was not yet comparable with adult pectoral muscle mass, at $20 \mathrm{~d}$ of age, they nevertheless comprised $15.9 \%$ of total lean dry body mass in nestlings (Fig. $2 A$ ). In the adult starlings, pectoral muscles represented $21 \%$ of lean dry body mass (data not shown).

\section{Resting Metabolic Rate and Its Relationship with Body Composition}

RMR increased significantly with age (Table 1), increasing by 3.6 times between 5 and $11 \mathrm{~d}$ of age and 1.5 times between 11 and $20 \mathrm{~d}$ of age. RMR was linearly related to fresh body mass in the three age classes (Fig. $3 A ; 5 \mathrm{~d}: r=0.83, F_{1,16}=33.3$,
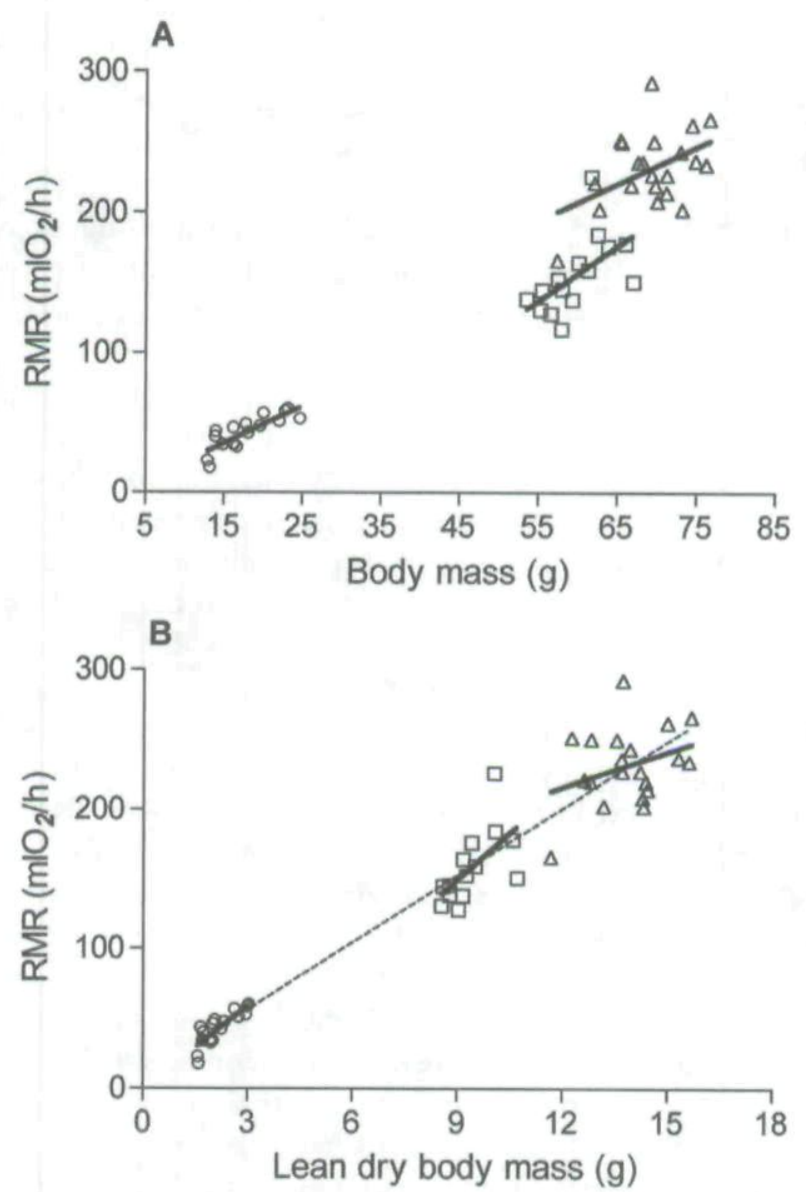

Figure 3. Relationship between resting metabolic rate (RMR) and (A) body mass and $(B)$ lean dry body mass in nestling at $5 \mathrm{~d}$ (circles), 11 $\mathrm{d}$ (squares), and $20 \mathrm{~d}$ (triangles) of age. In $A$, the slopes do not differ significantly, but the intercepts are different. In $B$, both slopes and intercepts do not differ significantly. The dotted line represents the overall relationship across age classes. See text for details. 
$P<0.0001$, intercept $=-5.5$, slope $=2.7 ; 11 \mathrm{~d}: r=0.57$, $F_{1,14}=6.2, P<0.05$, intercept $=-77.2$, slope $=3.9 ; 20 \mathrm{~d}$ : $r=0.48, F_{1,20}=5.6, P<0.05$, intercept $=50.2$, slope $=2.6$ ). The slopes of these relationships were not statistically different (ANCOVA, fresh body mass $\times$ age interaction, $P=0.7$ ) but there was a difference in intercept between the three age classes (age: $F_{2,52}=21.7, P<0.0001$; least square means: $5 \mathrm{~d}=$ $137.6 \pm 21.6 \mathrm{~mL} \mathrm{O}_{2} / \mathrm{h}, 11 \mathrm{~d}=127.2 \pm 8.1 \mathrm{~mL} \mathrm{O}_{2} / \mathrm{h}, 20 \mathrm{~d}=$ $175.2 \pm 13.3 \mathrm{~mL} \mathrm{O}_{2} / \mathrm{h}$ ). However, when performing the same analysis controlling for lean dry body mass, this age effect was not found (lean dry body mass $\times$ age interaction, $P=0.2$; age, $P=0.6$ ), confirming a linear increase in RMR with lean body mass (Fig. $3 B$; relationship across age stages, $r=0.97$, $F_{1,50}=792.2, P<0.0001$, intercept $=7.9$, slope $\left.=16.1\right)$.

Stepwise multiple regression models using independent principal component variables revealed that RMR was significantly related to four to five PC variables in each age class (Tables 24). At all ages, the first variable included in the model was PC1. This variable roughly showed the same eigenvectors for all organs and explained $45 \%-87 \%$ of total within-age variation in body-composition data. PC1 therefore reflects structural body size, and its relationship with RMR is not surprising. More interesting is the contribution of the other PC variables to variation in RMR because they reflect size-independent variation in specific organs.

Five-Day-Old Nestlings. In 5-d-old nestlings, the next variables contributing to variation in RMR after PC1 were, in descending order, PC8, PC9, PC6, and PC4 (Table 2). PC8 was mainly negatively influenced by lean dry carcass mass, suggesting that at $5 \mathrm{~d}$ of age, nestlings with light carcasses would have high RMR, perhaps reflecting the effect of the relatively large internal organs. PC9 was negatively related to RMR in the regression model (slope $=-22.6$ ). The implication of this relationship is that organ variables that were negatively related to PC9 (negative eigenvectors) were in fact positively correlated with RMR. PC9 was mainly under the influence of lean dry liver and leg mass. Therefore, individuals showing high RMR also had large livers and small legs. The next two variables significantly related to RMR were PC6 and PC4, both having negative slopes $($ PC6 $=-8.3$, PC9 $=-4.9)$. PC6 suggested a significant positive contribution of lean dry gizzard and heart mass to RMR variation. PC4 was also under the influence of these same organs but with a reversed pattern for lean dry gizzard mass, suggesting, in this case, a negative relationship with RMR variation. PC4 further suggested a positive association between RMR and lean dry intestine mass.

Therefore, RMR in 5-d-old nestlings was higher in individuals with relatively small carcasses and legs but relatively large livers, hearts, and intestines. Although mass variation in gizzard influenced two PC variables that were related to variations in RMR, the signal for this organ was mixed with both positive and negative influences and is thus difficult to interpret. Total variation in RMR explained by these PC variables was $88 \%$ (Table 2).
Table 2: Results of stepwise multiple regression on principal component (PC) variables explaining variability in resting metabolic rate within 5 -d-olds

\begin{tabular}{lccccc}
\hline & PC1 & PC8 & \multicolumn{1}{l}{ PC9 } & PC6 & \multicolumn{1}{l}{ PC4 } \\
\hline Eigenvalue & 7.805 & .018 & .007 & .050 & .140 \\
Percent & 86.7 & .2 & .1 & .6 & 1.6 \\
Slope & 3.8 & 17.4 & -22.6 & -8.3 & -4.9 \\
Cumulative $r^{2}$ & .77 & .80 & .83 & .85 & .88 \\
Eigenvectors: & & & & & \\
LD carcass & .35 & -.82 & -.32 & .03 & .06 \\
LD liver & .35 & .23 & -.52 & .29 & -.19 \\
LD heart & .33 & .14 & -.02 & -.47 & -.53 \\
LD kidney & .34 & .16 & -.01 & .20 & .19 \\
LD gizzard & .34 & .20 & -.22 & -.62 & .55 \\
LD pancreas & .30 & -.08 & .24 & .37 & .33 \\
LD pectoral & .34 & .39 & -.02 & .35 & -.05 \\
LD leg & .34 & -.04 & .68 & -.09 & .10 \\
LD intestine & .32 & -.16 & .26 & -.03 & -.46 \\
\hline
\end{tabular}

Note. Intercept $=42.7 . \mathrm{LD}=$ lean dry. Eigenvectors with values $\geq 0.4$ are highlighted in bold.

Eleven-Day-Old Nestlings. In 11-d-old nestlings, the next variables related to RMR after PC1 were PC3, PC4, and PC2. PC3 was under the strong positive influence of lean dry kidney mass and to a lesser extent lean dry liver mass, suggesting that individuals with large kidneys and livers tended to have high RMR. PC4 was positively related to lean dry pancreas and liver and negatively related to lean dry gizzard mass, while PC2, because of its negative regression slope $(-5.4)$, showed a positive influence of lean dry heart mass and a negative influence of lean dry gizzard and intestine mass on RMR. Thus, in 11d-old birds, individuals with a relatively large kidney, liver, pancreas, and heart but with a relatively small gizzard and intestine tended to have high RMR. Total variation in RMR explained by these four PC variables was 70\% (Table 3).

Twenty-Day-Old Nestlings. RMR in nestlings $20 \mathrm{~d}$ of age was also affected by three PC variables after PC1: PC4, PC2, and PC9. PC4 was strongly and positively influenced by lean dry kidney mass with a lesser negative influence of lean dry leg mass. PC2 was under the positive influence of lean dry pancreas mass and was negatively related to lean dry pectoral muscle mass. PC9 was related to RMR with a negative slope $(-32.0)$ and therefore suggested a strong positive influence of lean dry carcass mass and a lesser negative effect of lean dry pectoral muscle mass. As in the 11-d-old nestlings, individuals at $20 \mathrm{~d}$ of age that had a large kidney and pancreas were therefore likely to exhibit high levels of RMR. These individuals also tended to have a large carcass. Total variation in RMR explained by these four PC variables was 35\% (Table 4).

\section{Tissue Accretion and Resting Metabolic Rate}

Energy investment in tissue accretion between 5 and $11 \mathrm{~d}$ of age was estimated at $28.2 \mathrm{~kJ} / \mathrm{d}$. The liver, gizzard, leg, and 
Table 3: Results of stepwise multiple regression on principal component $(\mathrm{PC})$ variables explaining variability in resting metabolic rate within 11-d-olds

\begin{tabular}{lcccc}
\hline & PC1 & PC3 & PC4 & PC2 \\
\hline Eigenvalue & 4.009 & 1.281 & .954 & 1.649 \\
Percent & 44.5 & 14.2 & 10.6 & 18.3 \\
Slope & 7.2 & 8.9 & 12.0 & -5.4 \\
Cumulative $r^{2}$ & .41 & .52 & .63 & .70 \\
Eigenvectors: & & & & \\
$\quad$ LD carcass & .47 & -.01 & -.19 & .00 \\
LD liver & .30 & .41 & .40 & .10 \\
LD heart & .33 & -.05 & .05 & -.51 \\
LD kidney & -.003 & .81 & .13 & -.14 \\
LD gizzard & .20 & .12 & -.51 & .49 \\
LD pancreas & .29 & -.39 & .58 & .15 \\
LD pectoral & .44 & -.03 & -.03 & -.29 \\
LD leg & .46 & -.02 & -.33 & .002 \\
LD intestine & .21 & .06 & .28 & .60 \\
\hline
\end{tabular}

Note. Intercept $=156.5$. $L D=$ lean dry. Eigenvectors with values $\geq 0.4$ are highlighted in bold.

intestines accounted for $22.2 \%$ of this value. Between 11 and $20 \mathrm{~d}$ of age, the energy spent on tissue growth was much lower, with an estimated value of $11.95 \mathrm{~kJ} / \mathrm{d}$. Pectoral and leg muscle growth accounted for $43.2 \%$ of this estimate. The approximated cost of tissue deposition during the period from 5 to $11 \mathrm{~d}$ of age therefore represented $140.0 \%$ and $38.4 \%$ of RMR in 5- and 11-d-old nestlings, respectively (RMR here is the average of calculated range in $\mathrm{kJ} / \mathrm{d}$; Table 1). During the plateau phase of growth, energy invested in tissue development represented only $16.3 \%$ and $10.9 \%$ of RMR at 11 and $20 \mathrm{~d}$ of age, respectively.

\section{Discussion}

Early postnatal body composition and development in altricial species is characterized by a disproportionate stomach size and rapid growth of the digestive organs such as the liver ( $\mathrm{O}^{\prime} \mathrm{Connor}$ 1977; Ricklefs 1979; Lilja 1982, 1983; but see Ricklefs et al. 1998). Accordingly, in our study species, digestive organs (liver, pancreas, gizzard, and intestines) represented a substantial proportion (29\%) of lean dry body mass in 5-d-old nestlings. At $11 \mathrm{~d}$ of age, although nestling body mass was roughly half of average adult mass, liver, kidney, gizzard, and pancreas were already at or very close (i.e., $86 \%$ for kidney) to the final adult target mass.

Relative water content decreased in growing nestlings, which indicates an increase in the proportion of metabolically active tissues and general tissue maturation (Ricklefs 1967, 1979; Ricklefs and Webb 1985; Starck and Ricklefs 1998). As described by Weathers and Siegel (1995) and Weathers (1996) for altricial species (but see Mishaga and Whitford 1983 and Bech and Ostnes 1999 for exceptions), tissue maturation was paralleled by a linear increase in RMR with the development of body mass, presumably reflecting the accumulation of metabolically active tissues. However, a linear increase in RMR did not reflect equal growth of all organs. Indeed, during the linear growth phase, absolute growth rate ( $\mathrm{g}$ tissue added/d) was much higher in liver, gizzard, and intestine than in kidney and pancreas. During the plateau phase of growth, however, only pectoral muscles showed a marked increase in relative size. According to the "metabolic machinery" hypothesis, organs or tissues with high or disproportionate metabolic activity (i.e., high respiration rate relative to other organs or systems) are likely to correlate positively with overall resting or basal metabolism. Therefore, changes in tissue-synthesis rate or the metabolic intensity of specific organs between age classes, together with relative differences in organ mass, are likely to result in context-specific patterns of relationships between body composition and RMR, and this is exactly what we found, as we discuss below.

\section{Interactions between Body Composition and Resting Metabolic Rate}

Early in life there seems to be a predominant effect of the costs of synthesizing new tissues. Although our estimates of tissueaccretion costs are only approximations, they suggest that tissue growth represented a major contribution to RMR in young nestlings. Furthermore, the internal organs exhibiting the highest absolute growth rate between 5 and $11 \mathrm{~d}$ - the liver, gizzard, and intestine-were all identified as significant contributors to variation in RMR. The heart, an organ repeatedly reported as a significant contributor to the variation in BMR in adult animals (Daan et al. 1990; Weber and Piersma 1996; Burness et al. 1998; Chappell et al. 1999), was also highlighted as an important energy-consuming organ at this age. Bech and Ostnes (1999) found a positive correlation between RMR and both liver mass and intestine length in 15-d-old European shags (Phalacrocorax aristotelis), when they were still in the rapid linear phase of growth. A stepwise regression further identified

Table 4: Results of stepwise multiple regression on principal component (PC) variables explaining variability in resting metabolic rate within 20 -d-olds

\begin{tabular}{lcccc}
\hline & PC1 & PC4 & PC2 & PC9 \\
\hline Eigenvalue & 4.684 & .649 & 1.706 & .049 \\
Percent & 52.0 & 7.2 & 19.0 & .5 \\
Slope & 4.9 & 9.2 & 5.5 & -32.0 \\
Cumulative $r^{2}$ & .15 & .22 & .29 & .35 \\
Eigenvectors: & & & & \\
LD carcass & .40 & -.09 & -.29 & -.76 \\
LD liver & .32 & .06 & .39 & .04 \\
LD heart & .38 & -.06 & -.21 & -.11 \\
LD kidney & .30 & .79 & .15 & .04 \\
LD gizzard & .32 & .15 & .16 & -.01 \\
LD pancreas & .17 & -.33 & .54 & .08 \\
LD pectoral & .33 & .12 & -.44 & .53 \\
LD leg & .37 & -.40 & -.25 & .34 \\
LD intestine & .35 & -.24 & .34 & .04 \\
\hline
\end{tabular}

Note. Intercept $=231.5$. LD $=$ lean dry. Eigenvectors with values $\geq 0.4$ are highlighted in bold. 
the liver as the only organ having a significant effect on resting metabolism. Interestingly, a later study on the same species (Moe et al. 2004) revealed that when nestlings are food restricted during this period of rapid linear growth, there is a decline in the mass of several internal organs, including the liver, accompanied by a $37 \%$ decrease in RMR. Again, liver mass was found to be a significant contributor to the variation in RMR (Moe et al. 2004).

In 11-d-old starlings, when most internal organs have attained or are close to their final mass, and at $20 \mathrm{~d}$, just before fledging, a point were body composition is very close to adult organ proportions (see Vézina and Williams 2003 for adult data), the pattern of organs related to RMR was different than at $5 \mathrm{~d}$ of age. In 11-d-old nestlings, we found a predominance of the kidney, pancreas, liver, and heart contributing to variation in RMR, while kidney, pancreas, and carcass were highlighted at $20 \mathrm{~d}$. None of these internal organs were disproportionately large on a relative scale at this point, and by 11 $\mathrm{d}$, except for the heart and carcass, growth was completed in all these organs. As with the heart, the kidneys have also been highlighted as a significant contributor to variation in BMR or RMR in adult animals, either separately or in association with other organs (Daan et al. 1990; Weber and Piersma 1996; Burness et al. 1998; Chappell et al. 1999). These organs, although typically representing only $1 \%$ of total body mass in adult starlings (based on Vézina and Williams 2003 data), show high metabolic intensity in vitro (Krebs 1950; Schmidt-Nielsen 1984).

Interestingly, no effect of pectoral muscles on variation in RMR was detected at 11 or $20 \mathrm{~d}$ of age, even though these organs were the fastest-growing body components between these time points. In European starlings, heat production by shivering attains adult levels by $12 \mathrm{~d}$ of age (Ricklefs 1979; Clark 1982), while flight capability develops rapidly between 15 and $20 \mathrm{~d}$ of age (Ricklefs 1979). These organs are therefore already functional before attaining adult size. It is possible that most of the pectoral muscle growth happened between our RMR measurements at 11 and $20 \mathrm{~d}$ of age, thus preventing us from detecting muscle growth effects on RMR. However, according to our estimates, tissue accretion during the plateau phase of growth might have only represented $10 \%-16 \%$ of RMR. This suggests that the energy investment in muscle development was not high enough to overshadow the functional costs of other organs. Accordingly, in 11- and 20-d-old nestlings, individual variation in RMR appeared to be affected by the size of high-metabolic-intensity organs, a pattern typical of adult animals (Piersma 2002), rather than by the energetic costs of fast-growing body components.

Based on these findings, we suggest that RMR variation of growing starling nestlings highlights a transition in metabolic costs over time. During the linear phase of growth, energy is consumed mostly by tissue-synthesis processes with fastgrowing internal organs-such as liver, gizzard, and intestinehaving a large influence on the total energy used. Later, when nestlings reach the plateau phase of growth, the energy used is transferred to functional costs more typical of adult condition, with variations in mass of high-metabolic-intensity organs likely to affect variations in RMR.

\section{Context-Specific Nature of Relationships between Body Composition and Basal Metabolic Rate}

Our data have important implications in the context of understanding the basis of variation in basal or resting metabolic rates in animals. They highlight the context-specific nature of relationships between organ mass and BMR or RMR. Here, our data suggest a transition in the underlying causes of RMR variation, from the metabolic costs of growing new tissues in developing nestlings to that of functional and maintenance costs of organs and physiological functions in fully grown birds. In adult animals, physiological systems are typically flexible and can change rapidly and reversibly in response to specific conditions (Piersma and Lindström 1997; McKechnie et al. 2007), and this often includes significant organ atrophy and growth cycles (Secor et al. 1994; Piersma et al. 1999; Fox and Kahlert 2005). Furthermore, the direction of changes in different components may be opposite such that positive and negative changes in energy consumption can cancel each other out in terms of net effects on BMR (Selman and Evans 2005; Vézina and Williams 2005). Moreover, downregulation of BMR has been shown in certain species facing experimentally energydemanding situations, presumably as an energy-saving mechanism (Bautista et al. 1998; Deerenberg et al. 1998; Nudds and Bryant 2001; Wiersma et al. 2005), suggesting that short-term changes in BMR can also be independent of variation in body composition. The implications of all this are that the relationship between body composition and RMR or BMR depends on the specific physiological state of the animal at the time of measurement. Because body composition and tissue metabolic intensity are dynamic physiological traits, intra- or interspecific comparisons in BMR without consideration for the animal's physiological state is bound to be a complicated endeavor and, in our opinion, might produce seemingly contradictory results across different studies.

\section{Acknowledgments}

We are grateful to Wendell Challenger, Julian Christians, Kristin Cumming, and Mandy Hindle for help in the field and in the laboratory as well as for fruitful discussions. We also thank Tom Scott and Lee Struthers from the Pacific Agri-Food Research Center for providing the field laboratory, and we thank Maurine W. Dietz and two anonymous reviewers for constructive comments on an earlier version of this article. This research was funded by an operating Natural Sciences and Engineering Research Council (NSERC) grant to T.D.W. and postgraduate funding to F.V. from NSERC and FQRNT (Fonds Québécois de la Recherche sur la Nature et les Technologies). The writing phase of this article was supported by a VENI grant to F.V. from the Netherlands Organization for Scientific Research. 


\section{Literature Cited}

Bautista L.M., J. Tinbergen, P. Wiersma, and A. Kacelnik. 1998. Optimal foraging and beyond: how starlings cope with changes in food availability. Am Nat 152:543-561.

Bech C. and J.E. Ostnes. 1999. Influence of body composition on the metabolic rate of nestling European shags (Phalacrocorax aristotelis). J Comp Physiol 169:263-270.

Biebach H. 1979. Energetik des Brütens beim Star (Sturnus vulgaris). J Ornithol 120:121-138.

- 1984. Effect of clutch size and time of day on the energy expenditure of incubating starlings (Sturnus vulgaris). Physiol Zool 5:26-31.

Blem C.R. 1984. Ratios in avian physiology. Auk 101:153-155.

Burness G.P., R.C. Ydenberg, and P.W. Hochachka. 1998. Interindividual variability in body composition and resting oxygen consumption rate in breeding tree swallows, Tachycineta bicolor. Physiol Zool 71:247-256.

Chappell M.A., C. Bech, and W.A. Buttemer. 1999. The relationship of central and peripheral organ masses to aerobic performance variation in house sparrows. J Exp Biol 20: 2269-2279.

Clark L. 1982. The development of effective homeothermy and endothermy by nestling starlings. Comp Biochem Physiol A 73:253-260.

Daan S., D. Masman, and A. Groenewold. 1990. Avian basal metabolic rates: their association with body composition and energy expenditure in nature. Am J Physiol 259:R333-R340.

Deerenberg C., G.J.F. Overkamp, G.H. Visser, and S. Daan. 1998. Compensation in resting metabolism for experimentally increased activity. J Comp Physiol B 168:507-512.

Dietz M.W., R.H. Drent, and R.E. Ricklefs. 1995. Biphasic development of metabolic rate in young precocial birds: a possible physiological basis. Pp. 57-76 in M.W. Dietz. Development of Metabolism and Thermoregulation in Galliforms: Effects of Body Mass, Growth Rate and Functional Maturity. $\mathrm{PhD}$ diss. University of Utrecht.

Drent R.H. and S. Daan. 1980. The prudent parent: energetic adjustments in avian breeding. Ardea 68:225-252.

Dunn E.H. and I.L. Brisbin. 1980. Age-specific changes in the major body components and caloric values of herring gull chicks. Condor 82:398-401.

Fox A.D. and J. Kahlert. 2005. Changes in body mass and organ size during wing moult in non-breeding greylag geese Anser anser. J Avian Biol 36:538-548.

Hammond K.A., M.A. Chappell, R.A. Cardullo, R.-S. Lin, and T.S. Johnsen. 2000. The mechanistic basis of aerobic performance variation in red junglefowl. J Exp Biol 203:20532064.

Johnson M.S., S.C. Thomson, and J.R. Speakman. 2001. Limits to sustained energy intake. II. Inter-relationships between resting metabolic rate, life-history traits and morphology in Mus musculus. J Exp Biol 204:1937-1946.

Jolliffe I.T. 2002. Principal Component Analysis. 2nd ed. Springer, New York.

Kersten M. and T. Piersma. 1987. High levels of energy ex- penditure in shorebirds: metabolic adaptations to an energetically expensive way of life. Ardea 75:175-187.

Klaassen M. and R. Drent. 1991. An analysis of hatchling resting metabolism: in search of ecological correlates that explain deviations from allometric relations. Condor 93:612-629.

Konarzewski M. and J. Diamond. 1995. Evolution of basal metabolic rate and organ masses in laboratory mice. Evolution 49:1239-1248.

Krebs H.A. 1950. Body size and tissue respiration. Biochim Biophys Acta 4:249-269.

Lilja C. 1982. Postnatal growth and organ development in the fieldfare and the jackdaw (Turdus pilaris and Corvus monedula). Growth 46:367-387.

- 1983. A comparative study of postnatal growth and organ development in some species of birds. Growth 47:317339.

1997. Oxygen consumption and vital organ masses in young growing quail (Coturnix coturnix japonica). Acta Physiol Scand 160:113-114.

McKechnie A.E., K. Chetty, and B.G. Lovegrove. 2007. Phenotypic flexibility in the basal metabolic rate of laughing doves: response to short-term thermal acclimation. J Exp Biol 210:97-106.

Meerlo P., L. Bolle, G.H. Visser, D. Masman, and S. Daan. 1997. Basal metabolic rate in relation to body composition and daily energy expenditure in the field vole, Microtus agrestis. Physiol Zool 70:362-369.

Mishaga R.J. and W.G. Whitford. 1983. Temperature regulation and metabolism in developing white-necked ravens. Comp Biochem Physiol A 74:605-613.

Moe B., S. Brunvoll, D. Mork, T.E. Brobakk, and C. Bech. 2004. Developmental plasticity of physiology and morphology in diet-restricted European shag nestlings (Phalacrocorax aristotelis). J Exp Biol 207:4067-4076.

Moe B., E. Stolevik, and C. Bech. 2005. Ducklings exhibit substantial energy-saving mechanisms as a response to shortterm food shortage. Physiol Biochem Zool 78:90-104.

Nudds R.L. and D.M. Bryant. 2001. Exercise training lowers the resting metabolic rate of zebra finches, Taenipygia guttata. Funct Ecol 15:458-464.

O'Connor R.J. 1977. Differential growth and body composition in altricial passerines. Ibis 119:147-119.

Packard G.C. and T.J. Boardman. 1988. The misuse of ratio, indices, and percentages in ecophysiological research. Physiol Zool 61:1-9.

1999. The use of percentages and size-specific indices to normalize physiological data for variation in body size: wasted time, wasted effort? Comp Biochem Physiol A 122: 37-44.

Piersma T. 2002. Energetic bottlenecks and other design constraints in avian annual cycles. Integr Comp Biol 42:51-67.

Piersma T., L. Bruinzeel, R. Drent, M. Kertsen, J. Van der Meer, and P. Wiersma. 1996. Variability in basal metabolic rate of a long distance migrant shorebird (red knot, Calidris canutus) reflects shifts in organ sizes. Physiol Zool 69:191-217.

Piersma T. and J. Drent. 2003. Phenotypic flexibility and the 
evolution of organismal design. Trends Ecol Evol 18:228233.

Piersma T., G.A. Gudmundsson, and K. Lilliendahl. 1999. Rapid changes in the size of different functional organ and muscle groups during refueling in a long-distance migrating shorebird. Physiol Biochem Zool 72:405-415.

Piersma T. and A. Lindström. 1997. Rapid reversible changes in organ size as a component of adaptive behavior. Trends Ecol Evol 12:134-138.

Prinzinger R.A., A. Preßmar, and E. Schleucher. 1991. Body temperature in birds. Comp Biochem Physiol 99:499-506.

Pullar J.D. and A.F.J. Webster. 1977. The energy cost of fat and protein deposition in the rat. Br J Nutr 37:355-363.

Ricklefs R.E. 1967. Relative growth, body constituents, and energy content of nestling barn swallows and red-winged blackbirds. Auk 84:560-570.

- 1973. Patterns of growth in birds. II. Growth rate and mode of development. Ibis 115:177-201.

1979. Patterns of growth in birds. V. A comparative study of development in the starling, common tern, and Japanese quail. Auk 96:10-30.

Ricklefs R.E., J.M. Starck, and M. Konarzewski. 1998. Internal constraints on growth in birds. Pp. 266-287 in J.M. Starck and R.E. Ricklefs, eds. Avian Growth and Development: Evolution within the Altricial-Precocial Spectrum. Oxford University Press, New York.

Ricklefs R.E. and T. Webb. 1985. Water content, thermogenesis, and growth rate of skeletal muscles in the European starling. Auk 102:369-376.

Schmidt-Nielsen K. 1984. Scaling: Why Is Animal Size So Important? Cambridge University Press, New York.

. 1990. Animal Physiology: Adaptation and Environment. Cambridge University Press, Cambridge.

Scott I. and P.R. Evans. 1992. The metabolic output of avian (Sturnus vulgaris, Calidris alpina) adipose tissue liver and skeletal muscle: implications for BMR/body mass relationship. Comp Biochem Physiol 103:329-332.

Secor S.M., E.D. Stein, and J. Diamond. 1994. Rapid upregulation of snake intestine in response to feeding: a new model of intestinal adaptation. Am J Physiol 29:G695-G705.

Selman C. and P.R. Evans. 2005. Alterations in tissue aerobic capacity may play a role in premigratory fattening in shorebirds. Biol Lett 1:101-104.

Selman C., S. Lumsden, L. Bunger, W.G. Hill, and J.R. Speakman. 2001. Resting metabolic rate and morphology in mice
(Mus musculus) selected for high and low food intake. J Exp Biol 204:777-784.

Speakman J.R. and J. McQueenie. 1996. Limits to sustained metabolic rate: the link between food intake, basal metabolic rate, and morphology in reproducing mice, Mus musculus. Physiol Zool 69:746-769.

Starck J.M. and R.E. Ricklefs. 1998. Patterns of development: the altricial-precocial spectrum. Pp. 3-30 in J.M. Starck and R.E. Ricklefs, eds. Avian Growth and Development: Evolution within the Altricial-Precocial Spectrum. Oxford University Press, New York.

Steen J.B. and G.W. Gabrielsen. 1986. Thermogenesis in newly hatched eiders (Somaterina mollissima) and long-tailed (Clangula hyemalis) ducklings and barnacle (Branta leucpsis) goslings. Polar Res 4:181-186.

Vézina F. and T.D. Williams. 2003. Plasticity in body composition in breeding birds: what drives the metabolic costs of egg production? Physiol Biochem Zool 76:716-730.

2005. Interaction between organ mass and citrate synthase activity as an indicator of tissue maximal oxidative capacity in breeding European starlings: implications for metabolic rate and organ mass relationships. Funct Ecol 19: 119-128.

Weathers W.W. 1996. Energetics of postnatal growth. Pp. 461496 in C. Carey, ed. Avian Energetics and Nutritional Ecology. Chapman \& Hall, New York.

Weathers W.W. and R.B. Siegel. 1995. Body size establishes the scaling of avian postnatal metabolic rate: an interspecific analysis using phylogenetically independent contrasts. Ibis 137:532-542.

Weber T.P. and T. Piersma. 1996. Basal metabolic rate and the mass of tissues differing in metabolic scope: migrationrelated covariation between individual knots Calidris canutus. J Avian Biol 27:215-224.

Wiersma P., H.M. Salomons, and S. Verhulst. 2005. Metabolic adjustments to increasing foraging costs of starlings in a closed economy. J Exp Biol 208:4099-4108.

Williams J.B. and B.I. Tieleman. 2000. Flexibility in basal metabolic rate and evaporative water loss among hoopoe larks exposed to different environmental temperatures. J Exp Biol 203:3153-3159.

Williams T.D. and F. Vézina. 2001. Reproductive energy expenditure, intraspecific variation and fitness. Curr Ornithol 16:355-405.

Zar J.H. 1996. Biostatistical Analysis. Prentice Hall, London. 
Copyright of Physiological \& Biochemical Zoology is the property of University of Chicago Press and its content may not be copied or emailed to multiple sites or posted to a listserv without the copyright holder's express written permission. However, users may print, download, or email articles for individual use. 